\title{
Multi-Target Spectral Moment: QSAR for antiviral drugs vs. different viral species
}

\author{
Francisco J. Prado-Prado ${ }^{1,2, *}$, Fernanda Borges ${ }^{1}$, Eugenio Uriarte ${ }^{2}$, Lazaro G. Peréz-Montoto ${ }^{2}$ \\ and Humberto González-Díaz ${ }^{2,3 *}$. \\ ${ }^{1}$ Physic-Chemical Molecular Research Units, Department of Organic Chemistry, \\ Faculty of Pharmacy, University of Porto, 4150-047 Porto, Portugal. \\ ${ }^{2}$ Department of Organic Chemistry, University of Santiago de Compostela, \\ 15782 Santiago de Compostela, Spain. \\ ${ }^{3}$ Department of Microbiology \& Parasitology University of Santiago de Compostela, \\ 15782 Santiago de Compostela, Spain.
}

\begin{abstract}
The antiviral QSAR models have an important limitation today. They predict the biological activity of drugs against only one viral species. This is determined by the fact that most of the current reported molecular descriptors encode only information about the molecular structure. As a result, predicting the probability with which a drug is active against different viral species with a single unifying model is a goal of major importance. In this work, we use Markov Chain theory to calculate new multi-target spectral moments to fit a QSAR model for drugs active against 40 viral species. The model is based on 500 drugs (including active and non-active compounds) tested as antiviral agents in the recent literature; not all drugs were predicted against all viruses, but only those with experimental values. The database also contains 207 wellknown compounds (not as recent as the previous ones) reported in the Merck Index with other activities that do not include antiviral action against any virus species. We used Linear Discriminant Analysis (LDA) to classify all these drugs into two classes as active or non-active against the different viral species tested, whose data we processed. The model correctly classifies 5129 out of 5594 non-active compounds (91.69\%) and 412 out of 422 active compounds (97.63\%). Overall training predictability was $92.34 \%$. The validation of the model was carried out by means of external predicting series, the model classifying, thus, 2568 out of 2779 non-active compounds and 224 out of 229 active compounds. Overall training predictability was $92.82 \%$. The
\end{abstract}


present work reports the first attempts to calculate within a unified framework the probabilities of antiviral drugs against different virus species based on a spectral moment analysis.

Keywords: Multi-Target QSAR; Markov model; Antiviral drugs; Spectral Moments; Linear Discriminant Analysis.

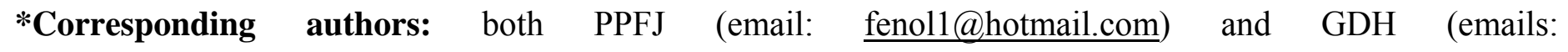
gonzalezdiazh@yahoo.es or humberto.gonzalez@usc.es) are the corresponding authors of this manuscript.

\section{Introduction}

Many viruses cause important human diseases and genetic diversity. Depending on the virus and the person's state of health, various viruses can infect almost any type of body tissue, from the brain to the skin. Viral infections cannot be treated with antibiotics; in fact, in some cases the use of antibiotics makes the infection worse. The vast majority of human viral infections can be effectively fought by the body's own immune system, with a little help in the form of proper diet, hydration and rest. Viruses represent a significant challenge to the medical science in fighting infectious diseases. The existing treatments against viral infections are often not entirely satisfactory, since most drugs that destroy viruses also affect the cells where they reproduce[1-4].

Computer-aided drug design techniques may play a very important role. These techniques are based on multi-target Quantitative Structure-Activity Relationship (mt-QSAR) studies. It means that they are models connecting the structure of drugs with the biological activity against different targets (microbial species in the case of antimicrobial drugs) $[5,6]$. This kind of study may also be useful in a Multi-Objective Optimization (MOOP) of desired properties or activity of drugs against different targets; see for instance the recent works carried out by Cruz-Monteagudo on the topic[7, 8]. In principle, up to date, there are over 1600 molecular descriptors that may be generalized and used to solve the former problem [9-12]. Many of these indices are known as Topological Indices (TIs) or simply invariants of a molecular graph, whose vertices are atoms weighed with physicochemical properties (mass, polarity, electronegativity or charge) [13]. Unfortunately, most antiviral QSAR studies reported up-to-date are based on molecular descriptors and databases of 
structurally parent compounds applicable to only one viral species. Consequently, the researcher interested in predicting, for instance, the antiviral activity for a given series of compounds, has to use/develop as many QSAR equations as combinations of compound families vs. viral species have to be predicted. Therefore, it is of major interest the development of a single unified equation explaining the antiviral activity of structurally heterogeneous series of compounds against as many viral species as possible [14, 15]. In fact, other mt-QSAR approaches, with demonstrated usefulness, have been introduced recently in Medicinal Chemistry [16-18]. We introduced a Markov Model encoding molecular backbones information. The method was named the MARCH-INSIDE, MARkovian CHemicals IN SIlico Design [19]. It allowed us to introduce matrix invariants such as stochastic entropies, potentials, and spectral moments for the study of molecular properties [20, 21]. Specifically, the stochastic spectral moments introduced by our group have been largely used for small molecules mt-QSAR problems including the design of fluckicidal, anticancer and antihypertensive drugs [22] [23-26]. The QSAR models based on different MARCH-INSIDE indices may be very useful to optimize important aspects such as activity, toxicity or pharmacokinetics using a single model in many bioorganic and medicinal chemistry problems such as: estimation of anticoccidial activity, modelling the interaction between drugs and HIV-packaging-region RNA, and predicting proteins and virus activity [27-31]. In three recent reviews, we have discussed the multiple applications of MARCH-INSIDE to classic QSAR, macromolecular QSAR, and specially mt-QSAR [32-34]. However, we have never used stochastic spectral moments before, in order to develop an mt-QSAR for antiviral drugs. In this work, we develop, for the first time, a single linear equation based on these previous ideas to predict the antiviral activity of drugs against different species.

\section{Methods}

\subsection{Markov Thermodynamics for drug-target step-by-step interaction}

Let us consider a hypothetical situation in which a drug molecule is free in the space at an arbitrary initial time $\left(t_{0}\right)$. It is then interesting to develop a simple stochastic model for a step-by-step interaction between the atoms of a drug molecule and a molecular receptor at the time of triggering the pharmacological effect. For the sake of simplicity, from now on, we are going to consider a general structure-less molecular receptor or drug-target, understanding by structure-less receptor a receptor whose chemical structure is not taken into consideration. In 
our model, we approach this problem considering the free energy ${ }^{\mathrm{k}} \mathrm{g}_{\mathrm{ij}}(\mathrm{s})$ of interaction between an atom in the drug and the drug receptor after k-steps or previous interactions. We state that ${ }^{k} \mathrm{~g}_{\mathrm{ij}}(\mathrm{s})$ is also a state function and the symbol g points precisely to Gibbs energy. S indicates that this energy depends on the specific drug target in different microbial species. Afterwards, the interaction has to define the free energy of interaction ${ }^{\mathrm{k}} \mathrm{g}_{\mathrm{ij}}(\mathrm{s})$ between the $\mathrm{j}$-th atom and the receptor for a specific microbial species (s) given that $\mathrm{i}$-th atom has been interacted/has interacted at a previous time $t_{k}$. So, one can suppose that atoms begin to bind to this receptor in discrete intervals of time $t_{k}$. However, there are several alternative ways in which such step-by-step binding process may occur. In this equation, the free energy ${ }^{1} \mathrm{~g}_{\mathrm{ij}}(\mathrm{s})$ can be defined by analogy as dependent on a constant for the atom-target interaction $\Gamma_{\mathrm{ij}}(\mathrm{s})[14,22]$ :

$$
{ }^{1} g_{i j}(s)=-R \cdot T \cdot \log ^{1} \Gamma_{i j}(s)
$$

The present approach to antimicrobial-receptor interaction has two main drawbacks. The first is the difficulty of defining the constants. In this work, we solve the first question by estimating the use of the occurrence ratio $n_{j}(s)$ of the $j$-th atom on active molecules against a given species (frequency of effective interactions) with respect to the number of atoms of the $\mathrm{j}$-th class in the molecules tested against the same $\operatorname{species} \mathrm{n}_{\mathrm{T}}(\mathrm{s})$. Consequently, one of the most important steps is the change on the value of the atomic weights used, ${ }^{k} g_{i j}(s)$, for different pathogen species. Regarding ${ }^{1} \Gamma_{\mathrm{ij}}(\mathrm{s})$, we must take into account that once the $\mathrm{j}$-th atoms have interacted, the preferred candidates for the next interaction are those $\mathrm{i}$-th atoms bound to $\mathrm{j}$ by a chemical bond [22]:

$$
{ }^{1} \Gamma_{i j}(s)=\left(\alpha_{i j} \cdot \frac{\mathrm{n}_{j}(s)}{\mathrm{n}_{\mathrm{T}}(s)}+1\right)=e^{\frac{{ }^{1} g_{i j}(s)}{R \cdot T}}
$$

Where $\alpha_{i j}$ are the elements of the atom adjacency matrix, $n_{j}(s), n_{T}(s)$, and ${ }^{1} g_{i j}(s)$ have been defined in the paragraph above, $\mathrm{R}$ is the universal gas constant, and $\mathrm{T}$ the absolute temperature. The number 1 is added to avoid forbidden negative values as inputs for the logarithmic function. The second problem is related to the description of the interaction process at higher times $t_{k}>t_{1}$. Therefore, Markov Chain theory enables a simple calculation of the probabilities with which the drug-receptor interaction takes place in the time until the 
antimicrobial effect is achieved. As depicted in Figure 1, this model deals with the calculation of the probabilities $\left({ }^{\mathrm{k}} \mathrm{p}_{\mathrm{ij}}\right)$ with which any arbitrary molecular atom $\mathrm{j}$-th binds to the structure-less molecular receptor given that other atom $\mathrm{i}$-th has been bound before; along discrete time periods $\mathrm{t}_{\mathrm{k}}(\mathrm{k}=1,2,3, \ldots) ;(\mathrm{k}=1$ in grey), $(\mathrm{k}=2$ in blue) and $(\mathrm{k}=3$ in red) throughout the chemical bonding system. According to the procedure described here, we consider the atoms of the molecule as states of the Markov Chain. The method arranges all the ${ }^{1} \mathrm{~g}_{\mathrm{ij}}(\mathrm{s})$ free energies of interaction as a squared table of $\mathrm{n} \times \mathrm{n}$ dimension. After the normalization of the matrix we can built up the corresponding stochastic matrix ${ }^{1} \Pi(\mathbf{s})$, which has the elements ${ }^{1} \pi_{\mathrm{ij}}(\mathrm{s})$ respectively. The matrix is called the 1-step drug-target interaction stochastic matrix. ${ }^{1} \Pi(\mathbf{s})$ is also built as a squared table of order $n$, where $n$ represents the number of atoms in the molecule. The elements ${ }^{1} \pi_{\mathrm{ij}}(\mathrm{s})$ of the 1 -step drug-target interaction stochastic matrix are the binding probabilities with which a $\mathrm{j}$-th atom binds to a structure-less molecular receptor given that other $\mathrm{i}$-th atoms have been interacted before at a time $\mathrm{t}_{1}=1[22]$ :

$$
{ }^{1} \pi_{i j}(s)=\frac{{ }^{1} g_{i j}(s)}{\sum_{a=1}^{n}{ }^{1} g_{i a}(s)}=\frac{\alpha_{i j} \cdot(-R T) \cdot \log \left(\frac{n_{j}(s)}{n(s)}+1\right)}{\sum_{a=1}^{n} \alpha_{i a} \cdot(-R T) \cdot \log \left(\frac{n_{a}(s)}{n_{T}(s)}+1\right)}=\frac{\alpha_{i j} \cdot \log \left(\frac{n_{j}(s)}{n_{T}}+1\right)}{\sum_{a=1}^{n} \alpha_{i a} \cdot \log \left(\frac{n_{j}(s)}{n_{T}(s)}+1\right)}
$$

Such a model is stochastic per se (probabilistic step-by-step atom-receptor interaction in time) but the molecular connectivity (the step-by-step atom union in space throughout the chemical bonding system) is also taken into account. One can calculate the atomic spectral moments ${ }^{k} \mu_{\mathrm{s}}(\mathrm{j})={ }^{\mathrm{k}} \pi_{\mathrm{jj}}(\mathrm{s})$, values on the main diagonal $(i=j)$ of the matrix, in order to numerically characterize the propensity with which a specific atom interacts several times with a drug receptor. In addition, the ${ }^{k} \mu_{s}(j)$ can be summed for specific atom sets (AS) to create local molecular descriptors ${ }^{k} \mu_{s}(A S)$ for the drug-target interaction. Herein, the AS used were as follows: halogens $(\mathrm{X})$, unsaturated carbons $\left(\mathrm{C}_{\mathrm{uns}}\right)$, saturated carbons $\left(\mathrm{C}_{\mathrm{sat}}\right)$, heteroatom $(\mathrm{Het})$, and hydrogen bound to heteroatom (H-Het). The corresponding symbols of the local spectral moments for these AS are: $\mu_{k}(\mathrm{X}, \mathrm{s})$, $\mu_{\mathrm{k}}\left(\mathrm{C}_{\mathrm{ins}}, \mathrm{s}\right), \mu_{\mathrm{k}}\left(\mathrm{C}_{\mathrm{sat}}, \mathrm{s}\right), \mu_{\mathrm{k}}($ Het, $\mathrm{s}), \mu_{\mathrm{k}}(\mathrm{H}-\mathrm{Het}, \mathrm{s})$. Finally, the sum of all atoms (it means that AS $=$ Total all atoms) is useful as a total molecular descriptor. 


$$
{ }^{k} \mu_{s}(A S)=\operatorname{Tr}\left(\left[{ }^{1} \Pi(\mathbf{s})\right]^{k}\right)_{j \in A S}=\operatorname{Tr}\left(\left[\begin{array}{ccccc}
{ }^{1} \pi_{11}(s) & { }^{1} \pi_{12}(s) & \cdot & \cdot & { }^{1} \pi_{1 n}(s) \\
{ }^{1} \pi_{21}(s) & { }^{1} \pi_{22}(s) & \cdot & \cdot & \cdot \\
\cdot & \cdot & \cdot & \cdot & \cdot \\
\cdot & \cdot & \cdot & \cdot & \cdot \\
{ }^{1} \pi_{n 1}(s) & \cdot & \cdot & \cdot & { }^{1} \pi_{n n}(s)
\end{array}\right)_{j \in A S}^{k}=\sum_{i=j \in A S}^{n} \pi_{i j}(s)\right.
$$

Figure 1 comes about here

\subsection{Statistical analysis}

As a continuation of the previous sections, we can attempt to develop a simple linear QSAR with the general formula:

$$
A c t v=a_{0} \cdot{ }^{0} \mu_{s}(A S)+a_{1} \cdot{ }^{1} \mu_{s}(A S)+a_{2} \cdot{ }^{2} \mu_{s}(A S)+a_{3} \cdot{ }^{3} \mu_{s}(A S)_{s} \ldots . .+a_{k} \cdot{ }^{k} \mu_{s}(A S)+b_{0}
$$

Here, ${ }^{k} \mu_{\mathrm{s}}(\mathrm{AS})$ are the spectral moments described above that act as molecule-target interaction descriptors specific for each drug-microbial species pair. We have selected Linear Discriminant Analysis (LDA) to fit the classification functions. The model deals with the classification of a set of compounds as active or non-active against different microbial species [35]. A dummy variable (Actv) has been used to codify the antimicrobial activity. This variable indicates either the presence $(\operatorname{Actv}=1)$ or absence $(\operatorname{Actv}=-1)$ of antimicrobial activity of the drug against specific species. In equation (5), $a_{k}$ are the coefficients of the classification function, determined by the least square method as implemented in the LDA module of the STATISTICA 6.0 software package [36]. Forward stepwise strategy was set as the one used for a variable selection[35]. The quality of LDA models was determined by examining Wilk's U statistic, Fisher ratio (F), and p-level (p). We have also inspected Accuracy, Sensitivity, and Specificity of the method. The validation of the model has been corroborated by external validation series [35].

\subsection{Data set}

The data set was made up of a set of marketed and/or very recently reported antiviral drugs which have low reported $\mathrm{IC}_{50}<10 \mu \mathrm{M}$ against different viruses. We collected drugs that are active or non-active against 40 different viral species. Altogether, the database contains 500 drugs (including active and non-active compounds) tested as antiviral agents in the recent literature; not all drugs were predicted against all viruses, only those with experimental values. The database also contains 207 well-known compounds (which are not as 
recent as the previous ones but largely known). These last compounds have been reported in the Merck Index with other activities that do not include antiviral action against any virus species and have been used as nonactive compounds [37]. Not all drugs have been tested in the literature against all listed species so we have been able to collect 9,024 cases (drug/species pairs) instead of 707 x 40 cases. The names or codes and activity for all compounds, as well as the references used to collect them are depicted in Table 1SM and Table 2SM of the supplementary material file.

\section{Results and discussion}

The main advantage of the present stochastic approach is the possibility of deriving average thermodynamic parameters depending on the probability of the MM states. The generalized parameters have a clearer physicochemical sense with respect to our previous ones [20, 38, 39]. More specifically, this work introduces for the first time a single linear QSAR equation model to predict the antiviral activity of drugs against different viral species. The best model found was:

$$
\begin{aligned}
& a c t v=-0.95^{0} \mu_{s}(H-H e t)+1.50^{2} \mu_{s}(H-H e t)-3.23^{0} \mu_{s}\left(C_{u n s}\right)-4.02^{0} \mu_{s}\left(C_{s a t}\right)-0.47^{1} \mu_{s}(T)+10.34^{0} \mu_{s}(T)+0.74^{5} \mu_{s}(X)-8.88 \\
& \lambda=0.51 \quad \chi^{2}=4024.83 \quad p<0.001
\end{aligned}
$$

In the model, the coefficient $\lambda$ is the Wilk's statistic; statistic for the overall discrimination, $\chi^{2}$ is the Chisquare, and $p$ the error level. In this equation, ${ }^{\mathrm{k}} \mu_{\mathrm{s}}$ have been calculated for the total (T) of atoms in the molecule or for specific collections of atoms. These collections are atoms with a common characteristic, for instance: hydrogen bound to heteroatom $(\mathrm{H}-\mathrm{Het})$, saturated Carbon atoms $\left(\mathrm{C}_{\text {sat }}\right)$, halogen atoms $(\mathrm{X})$ and unsaturated carbon atoms $\left(\mathrm{C}_{u n s}\right)$. The model correctly classifies 5129 out of 5594 non-active compounds (91.69\%) and 412 out of 422 active compounds (97.63\%). Overall training predictability was $92.34 \%$. The validation of the model was carried out by means of external predicting series, the model classifying, thus, 2 568 out of 2779 non-active compounds and 224 out of 229 active compounds. Overall training predictability was $92.82 \%$ see Table 1 . The results obtained for this LDA-QSAR model (levels of Accuracy, Sensitivity, and Specificity) are similar to the results previously obtained for other LDA-QSAR models [40-73] based on different databases that have been accepted in the literature.

\section{Table 1 comes about here}


The most interesting characteristic of the present model is that the ${ }^{\mathrm{k}} \mu_{\mathrm{s}}$ used as molecular descriptors depend both on the molecular structure of the drug and the viral species against which the drug must act. The codification of the molecular structure is basically due to the use of the adjacent factor $\alpha_{\mathrm{ij}}$ to encode an atomatom bond, a molecular connectivity. The other aspect that allows encoding molecular structural changes is that the spectral moment ${ }^{\mathrm{k}} \mu_{\mathrm{s}}$ are atom-class specific. This property is related to the definition of the ${ }^{\mathrm{k}} \mu_{\mathrm{s}}$. The values of these species and specific atomic standard free energies reported herein for the first time are given in Table 2 for some atoms and more than 40 species. For example, one change in the molecular structure of, e.g. $\mathrm{S}$ for $\mathrm{O}$, necessarily implies a change in the moments of interaction. Moreover, the most interesting fact is that ${ }^{\mathrm{k}} \mu_{\mathrm{s}}$ are the molecular descriptors reported for antimicrobial mt-QSAR studies able to distinguish among a large number of viral species.

\section{Table 2 comes about here}

As an end result of the abovementioned flexible definition of the present approach, it has been possible to model for the first time some heterogeneous and diverse viral data for over 9000 cases. In order to show how to use the model we include the atoms results for statistical values for different virus species in Table $\mathbf{3}$ in order to observe the behaviour of our model. The posterior validation probabilities predicted for every drugspecies pair are depicted in Table 2SM of the supplementary material file. The present work is the first reported unifying model, using moment's ${ }^{\mathrm{k}} \mu_{\mathrm{s}}$ as a molecular descriptor that allows a predicting antifungal activity of any organic compound against a very large diversity of viral pathogens.

\section{Table 3 comes about here}

\section{Conclusion}

The present mt-QSAR methodology with a very large data set improves significantly the previous QSAR models and may be useful to perform MOOP of drug activity against different viral species. It determines that the mt-QSAR methodology may be able to predict the biological activity of drugs in more general situations than the traditional QSAR models, whose greatest limitation is that it predicts the biological activity of drugs against only one viral species. Such QSAR models improve performance by increasing the database, with very clear results. This mt-QSAR methodology improves models using spectral moments as a molecular descriptor 
that allows predicting antiviral activity of any organic compound against a very large diversity of viral pathogens.

\section{Acknowledgments}

The authors are sincerely grateful for the kind attention as well as the useful comments made by Editor Prof. A. Monge-Vega and two unknown referees. Prado-Prado, F. acknowledges the financial support from the Xunta de Galicia for a one-year post-doctoral position (Research Project IN89A 2008/75-0). González-Díaz, H. acknowledges the financial support from the Isidro Parga Pondal Programme and one-year post-doctoral position (Research Project IN89A 2008/117-0), both financed by the Xunta de Galicia and the European Research funds from the European Social Fund (ESF).

\section{References}

[1] W.S. Huang, S.N. Lu, J.H. Wang, C.M. Lee, H.D. Tung, T.M. Chen, C.S. ChangChien, Hepatogastroenterology., 52 (2005) 893.

[2] T. Watkins-Riedel, P. Ferenci, P. Steindl-Munda, M. Gschwantler, C. Mueller, M. Woegerbauer, Clin. Infect. Dis., 39 (2004) 1754.

[3] K. Salminen, K. Sadeharju, M. Lonnrot, P. Vahasalo, A. Kupila, S. Korhonen, J. Ilonen, O. Simell, M. Knip, H. Hyoty, J. Med. Virol., 69 (2003) 91.

[4] G. Valet, H. Kahle, F. Otto, E. Brautigam, L. Kestens, Methods Cell Biol., 64 (2001) 487.

[5] F.J. Prado-Prado, H. Gonzalez-Diaz, O.M. de la Vega, F.M. Ubeira, K.C. Chou, Bioorg. Med. Chem., 16 (2008) 5871.

[6] F.J. Prado-Prado, O.M. de la Vega, E. Uriarte, F.M. Ubeira, K.C. Chou, H. Gonzalez-Diaz, Bioorg. Med. Chem., 17 (2009) 569.

[7] M. Cruz-Monteagudo, F. Borges, M.N. Cordeiro, J.L. Cagide Fajin, C. Morell, R.M. Ruiz, Y. CanizaresCarmenate, E.R. Dominguez, J Comb Chem, 10 (2008) 897.

[8] M. Cruz-Monteagudo, F. Borges, M.N. Cordeiro, J. Comput. Chem., 29 (2008) 2445.

[9] R. Todeschini, V. Consonni, Handbook of Molecular Descriptors, Wiley-VCH, 2002.

[10] H. Kubinyi, J. Cancer Res. Clin. Oncol., 116 (1990) 529.

[11] M.P. González, A.H. Morales, H. González-Díaz, Polymer, 45 (2004) 2073.

[12] Y. Marrero-Ponce, R.M. Marrero, F. Torrens, Y. Martinez, M.G. Bernal, V.R. Zaldivar, E.A. Castro, R.G. Abalo, J Mol Model (Online) (2005) 1.

[13] E. Estrada, E. Molina, J. Chem. Inf. Comput. Sci., 41 (2001) 791.

[14] H. González-Díaz, F.J. Prado-Prado, L. Santana, E. Uriarte, Bioorg. Med. Chem., 14 (2006) 5973.

[15] H. González-Díaz, F. Prado-Prado, J. Comput. Chem., 29 (2008) 656.

[16] Y. Marrero-Ponce, H.G. Diaz, V.R. Zaldivar, F. Torrens, E.A. Castro, Bioorg. Med. Chem., 12 (2004) 5331.

[17] E. Molina, H. González-Díaz, M.P. Gonzalez, E. Rodriguez, E. Uriarte, J. Chem. Inf. Comput. Sci., 44 (2004) 515.

[18] H. González-Díaz, A. Perez-Bello, E. Uriarte, Y. Gonzalez-Diaz, Bioorg. Med. Chem. Lett., 16 (2006) 547. 


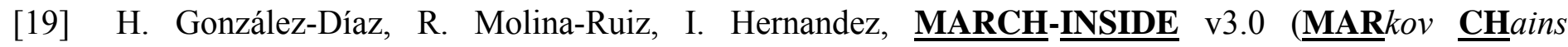
INvariants for SImulation \& DEsign); Windows supported version under request to the main author contact email: gonzalezdiazh@yahoo.es, 2007.

[20] H. González-Díaz, G. Aguero, M.A. Cabrera, R. Molina, L. Santana, E. Uriarte, G. Delogu, N. Castanedo, Bioorg. Med. Chem. Lett., 15 (2005) 551.

[21] R. Ramos de Armas, H. González-Díaz, R. Molina, M. Perez Gonzalez, E. Uriarte, Bioorg. Med. Chem., 12 (2004) 4815.

[22] F. Prado-Prado, H. González-Díaz, L. Santana, E. Uriarte, Bioorg. Med. Chem., 15 (2007) 897.

[23] H. González-Díaz, E. Uriarte, Bioorg. Med. Chem. Lett., 15 (2005) 5088.

[24] H. González-Díaz, O. Gia, E. Uriarte, I. Hernadez, R. Ramos, M. Chaviano, S. Seijo, J.A. Castillo, L. Morales, L. Santana, D. Akpaloo, E. Molina, M. Cruz, L.A. Torres, M.A. Cabrera, J Mol Model 9(2003) 395.

[25] H. González-Díaz, L. Saiz-Urra, R. Molina, L. Santana, E. Uriarte, Journal of proteome research, 6 (2007) 904.

[26] L. Saiz-Urra, H. González-Díaz, E. Uriarte, Bioorg. Med. Chem., 13 (2005) 3641.

[27] H. González-Díaz, R. Molina, E. Uriarte, Bioorg. Med. Chem. Lett., 14 (2004) 4691.

[28] H. González-Díaz, G. Ferino, G. Podda, E. Uriarte, ECSOC, 12 (2008) G1:1.

[29] H. González-Díaz, A. Sanchez-Gonzalez, Y. Gonzalez-Diaz, J. Inorg. Biochem., 100 (2006) 1290.

[30] H. González-Díaz, M.A. Cabrera-Pérez, G. Agüero-Chapín, M. Cruz-Monteagudo, N. CastañedoCancio, M.A. del Río, E. Uriarte, Chemometrics Intellig. Lab. Syst., 94 (2008) 160.

[31] M. Cruz-Monteagudo, H. González-Díaz, G. Agüero-Chapin, L. Santana, F. Borges, R.E. Domínguez, G. Podda, E. Uriarte, J. Comput. Chem., 28 (2007) 1909.

[32] H. González-Díaz, Y. González-Díaz, L. Santana, F.M. Ubeira, E. Uriarte, Proteomics, 8 (2008) 750.

[33] H. Gonzalez-Diaz, F. Prado-Prado, F.M. Ubeira, Curr Top Med Chem, 8 (2008) 1676.

[34] H. González-Díaz, S. Vilar, L. Santana, E. Uriarte, Curr Top Med Chem, 7 (2007) 1025.

[35] H. Van Waterbeemd, in: H. Van Waterbeemd (Ed.), Chemometric methods in molecular design, WileyVCH, New York, 1995, p. 265.

[36] StatSoft.Inc., STATISTICA (data analysis software system), version 6.0, www.statsoft.com.Statsoft, Inc., 2002.

[37] W.G. Town, Journal of chemical information and computer sciences, 44 (2004) 1883.

[38] H. González-Díaz, M. Cruz-Monteagudo, R. Molina, E. Tenorio, E. Uriarte, Bioorg. Med. Chem., 13 (2005) 1119.

[39] M. Cruz-Monteagudo, H. González-Díaz, Eur. J. Med. Chem., 40 (2005) 1030.

[40] E. Estrada, S. Vilar, E. Uriarte, Y. Gutierrez, J. Chem. Inf. Comput. Sci., 42 (2002) 1194.

[41] S. Vilar, G. Cozza, S. Moro, Curr Top Med Chem, 8 (2008) 1555.

[42] S. Vilar, E. Estrada, E. Uriarte, L. Santana, Y. Gutierrez, Journal of chemical information and modeling, 45 (2005) 502.

[43] S. Vilar, H. Gonzalez-Diaz, L. Santana, E. Uriarte, J. Comput. Chem., 29 (2008) 2613.

[44] S. Vilar, E. Quezada, L. Santana, E. Uriarte, M. Yanez, N. Fraiz, C. Alcaide, E. Cano, F. Orallo, Bioorg. Med. Chem. Lett., 16 (2006) 257.

[45] S. Vilar, L. Santana, E. Uriarte, J. Med. Chem., 49 (2006) 1118.

[46] J.A. Castillo-Garit, Y. Marrero-Ponce, J. Escobar, F. Torrens, R. Rotondo, Chemosphere, 73 (2008) 415.

[47] J.A. Castillo-Garit, Y. Marrero-Ponce, F. Torrens, Bioorg. Med. Chem., 14 (2006) 2398.

[48] J.A. Castillo-Garit, Y. Marrero-Ponce, F. Torrens, R. Garcia-Domenech, J. Pharm. Sci., 97 (2008) 1946.

[49] J.A. Castillo-Garit, Y. Marrero-Ponce, F. Torrens, R. Garcia-Domenech, V. Romero-Zaldivar, J. Comput. Chem., 29 (2008) 2500.

[50] J.A. Castillo-Garit, Y. Marrero-Ponce, F. Torrens, R. Rotondo, J. Mol. Graph. Model., 26 (2007) 32.

[51] Y. Marrero Ponce, J.A. Castillo Garit, D. Nodarse, Bioorg. Med. Chem., 13 (2005) 3397.

[52] Y. Marrero-Ponce, J.A. Castillo-Garit, J. Comput. Aided Mol. Des., 19 (2005) 369.

[53] Y. Marrero-Ponce, J.A. Castillo-Garit, E. Olazabal, H.S. Serrano, A. Morales, N. Castanedo, F. IbarraVelarde, A. Huesca-Guillen, E. Jorge, A. del Valle, F. Torrens, E.A. Castro, J. Comput. Aided Mol. Des., 18 (2004) 615. 
[54] Y. Marrero-Ponce, J.A. Castillo-Garit, E. Olazabal, H.S. Serrano, A. Morales, N. Castanedo, F. IbarraVelarde, A. Huesca-Guillen, A.M. Sanchez, F. Torrens, E.A. Castro, Bioorg. Med. Chem., 13 (2005) 1005.

[55] Y. Marrero-Ponce, R. Medina-Marrero, J.A. Castillo-Garit, V. Romero-Zaldivar, F. Torrens, E.A. Castro, Bioorg. Med. Chem., 13 (2005) 3003.

[56] Y. Marrero-Ponce, A. Meneses-Marcel, J.A. Castillo-Garit, Y. Machado-Tugores, J.A. Escario, A.G. Barrio, D.M. Pereira, J.J. Nogal-Ruiz, V.J. Aran, A.R. Martinez-Fernandez, F. Torrens, R. Rotondo, F. IbarraVelarde, Y.J. Alvarado, Bioorg. Med. Chem., 14 (2006) 6502.

[57] K.C. Chou, H.B. Shen, Biochem. Biophys. Res. Commun. (2006).

[58] H. Shen, K.C. Chou, Biochem. Biophys. Res. Commun., 334 (2005) 288.

[59] M. Wang, J. Yang, Z.J. Xu, K.C. Chou, J. Theor. Biol., 232 (2005) 7.

[60] K.C. Chou, H.B. Shen, J. Cell. Biochem. (2006).

[61] S.Q. Wang, J. Yang, K.C. Chou, J. Theor. Biol. (2006).

[62] H.B. Shen, K.C. Chou, Biochem. Biophys. Res. Commun., 337 (2005) 752.

[63] K.Y. Feng, Y.D. Cai, K.C. Chou, Biochem. Biophys. Res. Commun., 334 (2005) 213.

[64] Y.D. Cai, K.Y. Feng, W.C. Lu, K.C. Chou, J. Theor. Biol. (2005).

[65] Y.D. Cai, K.Y. Feng, W.C. Lu, K.C. Chou, J. Theor. Biol., 238 (2006) 172.

[66] H.B. Shen, K.C. Chou, Bioinformatics, 22 (2006) 1717.

[67] H.B. Shen, J. Yang, K.C. Chou, Amino Acids, 33 (2007) 57.

[68] J. Chen, H. Liu, J. Yang, K.C. Chou, Amino Acids, 33 (2007) 423.

[69] H.B. Shen, J. Yang, K.C. Chou, Expert review of proteomics, 4 (2007) 453.

[70] H.B. Shen, K.C. Chou, Biochem. Biophys. Res. Commun., 363 (2007) 297.

[71] T.L. Zhang, Y.S. Ding, K.C. Chou, J. Theor. Biol., 250 (2008) 186.

[72] Y.S. Ding, T.L. Zhang, K.C. Chou, Protein and peptide letters, 14 (2007) 811.

[73] H.B. Shen, K.C. Chou, Protein Eng Des Sel, 20 (2007) 561.

\section{LEGENDS FOR TABLES TO BE INSERTED IN THE TEXT.}

Table 1. Results of the model, analysis, validation.

Table 2. Standard atomic free energy values for atom-receptor interactions.

Table 3. Atoms results for statistical values for different virus species. 